\title{
Strategies and Clinical Applications of Next Generation Sequencing
}

\author{
Shohreh Khorshidii ${ }^{1, *}$, Alireza Palangi ${ }^{1}$ \\ ${ }^{1}$ Research and Development Department, Saman Tajhiz Noor Laboratory \\ Diagnostic Network Company, Tehran, Iran \\ *Corresponding author: Shohreh Khorshidi, Research and Development Department, \\ Saman Tajhiz Noor Laboratory Diagnostic Network Company, No.16, 10th Alley, \\ Bokharest St, Arjantin Sq, Tehran, Iran. P.0. Box: 1514734711, Tel.: +982185518; \\ Fax: +982188510327; E-mail: Shohre.khorshidi@gmail.com
}

DOI: 10.30699 /acadpub.mci.4.5

Submitted: 29 August 2018

Revised: 18 September 2018

Accepted: 25 September 2018

e-Published: 1 October 2018

\section{Keywords:}

High-Throughput

Nucleotide Sequencing

Whole Genome Sequencing

Whole Exome Sequencing

Clinical Application

\begin{abstract}
DNA sequencing is one of the great valuable techniques in molecular biology, which can be used to detect the sequence of nucleotides in a DNA fragment. The high-throughput sequencing known as Next Generation Sequencing (NGS) revolutionized genomic research and molecular biology; therefore, the whole human genome can be sequenced with a low cost in several days. NGS technology is similar to the traditional method, Sanger, which detects small DNA fragments by emitted signals at the time of synthesis of each fragment (from the DNA template), but the difference is that NGS can determine the massive simultaneous sequencing in a few days with high accuracy and the results are directly detected without the need for electrophoresis. In fact, NGS technology combines a variety of steps such as sample preparation, fragmentation of the sample of the studied genome, attachment of adapter to the ends of the fragments, imaging, and data analyses. In recent years, NGS technology continuously expanded the range of applications in different fields by reducing costs, increasing rates, and improving the quality of the data. The current review provided the potential applications of the NGS technology by emphasizing the diagnosis of the genetic diseases, identification of several types of cancers, prenatal screening, epigenetic modifications, personalized medicine, and identification of pathogens.
\end{abstract}

(C) 2018. Multidisciplinary Cancer Investigation

\section{INTRODUCTION}

In the early 1970s, DNA sequencing was evolved from the Maxam-Gilbert and the Sanger-Coulson methods. The Maxam-Gilbert approach was based on the radioactive labeling at the end of DNA fragments targeted to specific chemical cleavage followed by gel electrophoresis to separate the reaction products and subsequently visualized by film autoradiography. The Sanger-Coulson used a specific primer to begin the amplification at a particular position along the DNA template, and also employed the dideoxy terminator for DNA molecule that caused base-specific termination of synthesized DNA with the various labels for each nucleotide and finally by the capillary electrophoresis (CE) separated the chain termination products [1-3]. The Sanger DNA sequencing can accurately read 700$900 \mathrm{bp}$ and is therefore appropriate for a particular gene sequencing. The Sanger dideoxy termination was selected as the pivotal procedure for DNA sequencing due to less chemicals and higher efficiency [4].

Despite the widespread application of Sanger sequencing in the laboratories, this technique is no longer responsive to the needs of the researchers due to some limitations such as low throughput, low speed, high cost, and timing. In order to 
overcome the obstacles and improve the quality of information, a cost effective, high throughput, quick, and high accuracy technique was required that was also capable of sequencing with a little bit of genomic sample, which led to the discovery of a new technology, or a new generation of sequencing in 2005 referred to as next generation sequencing (NGS) $[4,5]$. NGS, also known as massively parallel sequencing is a kind of DNA sequencing technology that produces short sequences by immobilizing millions of amplified DNA fragments on an array to determine sequence in a single run $[6,7]$. This progressive technology revolutionized genomic research, biomedicine, and molecular biology, compared with the traditional sequencing methods [8].

NGS is faster than the Sanger dideoxy sequencing since the chemical reaction and signal detection are merged with each other and minimize the need for the fragment-cloning methods used with the Sanger sequencing. Among them, Illumina/ Solexa, Roche/LS454, ABI/SOLiD, and Helicos are the main technologies [9]. NGS is an efficient and promising tool to capture a large amount of genomic information and now widely applied in clinics in many fields such as molecular diagnostics, identification of polymorphisms and their association with Mendelian and complex genetic diseases, identification of several types of cancers, understanding RNA structure, transcriptomics, pathogen detection, prenatal screening, epigenetic modifications, personalized medicine, etc. [10, 11]. The current review represented the potentialities and clinical applications of NGS technology and the power of this novel genomic tool.

\section{Overview of NGS Technology}

NGS workflow includes four major steps: sample preparation, library construction, sequencing, and data analysis [12]. The process begins with dsDNA, RNA, and smaller portions of the genome as a starting material extracted from a sample to provide a template $[13,14]$. Typically, the main step in sample preparation is fragmentation and size selection of the target sequences performed by chemical, enzymatic, and physical methods. In general, the physical and enzymatic manners are performed by sonication and using the endonucleases or transposases, respectively [15]. Subsequently, a certain size range of adapters is ligated to both ends of DNA fragments to construct the library, and the suitable library size is determined according to the length of insert size and the sequencing application [15]. Following adapter ligation, these libraries are targeted for sequencing directly or pre-amplified on the flowcell or the bead surface prior to sequencing to generate clusters based on the protocol and sequencing platform $[15,16]$. Subsequently, the generated data should be imagined and analyzed by specific software to align with a reference genome or classified as a de novo assembly in the absence of reference genome [17]. Sequencing for de novo assembly is often performed when the microorganisms are uncharacterized or the purpose is to find out the genomic content and functional potential of the organism under exploration [9]. Therefore, improvements in bioinformatic tools as well as sequencing technology probably boost the success rate of sequencing.

Most NGS technologies use sequencing by synthesis approach [18]. In other words, to sequence DNA fragments, they should be bounded to an array, then labeled nucleotides have to be added by DNA polymerase and accordingly, high-resolution camera detects the signal from nucleotides; then after, the sequence at each spot can be interpreted by a specific computer program in order to read the DNA sequence [18]. There are various platforms or sequencers that differ in their throughput capabilities, read length, time per run and accuracy [18]; and therefore, researchers can choose one of them based on their needs.

\section{Quality Control (QC) of NGS Technology}

Since NGS workflows are complex and there is a lack of quality control programs in sequencing experiments, it is quite pivotal to set up and improve the procedures for standardization as well as quality documentation. Besides, verification and validation of sequenced data to obtain the reliable and reproducible data are crucial points [19]. Furthermore, quality control programs in NGS include several check points, which should be examined after each step such as sample preparation and library construction, before and after the sequencing run [11]. These can differ depending on the selected approach and sequencers, but generally comprise measurement of sample quality, quantity, purity, and integrity to ensure that samples with the appropriate quality maintained along the workflow [20]. Following the sample quality control, there is another QC check point in the library preparation in 
NGS workflow in order to guarantee the size, purity, concentration and efficiency of ligated adaptors according to the platform requirements [21]. The last stage of QC prior to the sequencing run and size selection of amplified fragments is performed in order to remove all contaminants such as unligated adapters and biases in base composition [19, 22]. Finally, after sequencing run, it is necessary to verify and validate the obtained results using an alternative technology such as pyrosequencing [21].

Moreover, there are various kinds of software tools that can focus on quality features of NGS data $[19,20,23]$. One of the most common software to evaluate the sequenced data with a known reference genome is FastQC and also in the absence of reference genome, some pre-processing tools exist that perform in the k-mer space to assess the quality parameters such as over-represented sequences and sequencing errors to remove the bad quality reads and trimming [23-25].

\section{Limitations of NGS Technology}

In addition to the advantages of NGS technology mentioned in the introduction section, the most important challenge that can be addressed is the data analysis that requires advanced computers, specialized software, fast data processing, large data storage capabilities, and individuals experienced with NGS data analysis approaches especially regarding bioinformatics and troubleshooting to analyze and clinically interpret the data [26].

\section{Strategies of NGS Technology}

Genomics experiments are mainly interpretative and success of all experimental designs is very important both for researchers and clinicians; therefore, choosing a sequencing strategy that matches with the goal of project should be prioritized. The technology of NGS follows one of the two general strategies: whole-genome sequencing (WGS) and targeted sequencing $[27,28]$. The first approach evaluates the entire genome and contains both gene-coding and non-coding regions [29]. Targeted sequencing utilizes target-specific primers for Polymerase Chain Reaction (PCR) amplification and selectively amplifies genomic areas of interest [9].

Potential-targeted strategy for NGS technology is exome sequencing, which focuses on the coding regions of the genome and can also involve either the whole exome sequencing (WES) or a panel of genes [29]. One of the main challenges for clinicians is choosing between region specific sequencing and WES, according to their applications and characteristics. Therefore, WES seems to be more cost-effective than region specific sequencing, but a region specific method has a much higher coverage of all the specific genes using the complementary approaches containing the Sanger sequencing or long-range PCR to obtain more confident results $[30,31]$.

Whole transcriptome sequencing or RNA-Seq is another kind of sequencing that reveals the presence and quantity of RNA in a biological sample and can evaluate the gene expression and alternative splice variants $[32,33]$.

\section{Clinical Applications of NGS Technology}

There are many potential applications of NGS in clinical practice due to its high-throughput and costeffectiveness in comparison with traditional Sanger sequencing that some of its applications were summarized in the current review.

\section{Detection of Gene Variations}

Since most of diseases have a genetic basis, identification of genetic variants related to such diseases is very important and is performed by genome-wide association studies (GWAS), but detection of rare and structural variants is not possible with the genotyping arrays and needs a new technology with the potential capability of WGS [34]. Although there is a wide spectrum of DNA variations in a human genome such as insertions/ deletions (indels), substitutions, and arrangements (inversions and translocations), which some of them like substitutions and small indels cannot be detected by routine sequencing methods, researchers, with the advent of NGS technology, can capture a range of novel mutations and disease causing genes by investigation of the full genome or exome without bias [35]. For instance, by applying the WES, the causal variants of Miller syndrome, as the first rare Mendelian disorder, were identified [36]. Although WES encompasses the protein-coding regions of the genome, they may not be completely covered due to the presence of the high GC content and repetitive sequences, which are poorly sequenced $[35,36]$.

\section{Oncology}

Cancers are induced by a broad spectrum of genomic alterations including point mutations, deletions, insertions, copy number alterations, and structural 
variations, which can be somatic or inheritable. Therefore, genomics and transcriptomics (RNA) data of cancer cells and structures with new DNA sequencing technologies (NGS) coupled with powerful bioinformatic tools provide opportunities to understand pathogenesis, diagnosis, management, treatment of disease, and improvement of the personalized treatment strategies [36, 37]. These technologies have the potential ability to identify the novel mutations and alterations in the cancer genome through whole-genome and whole-exome methods in order to distinguish the somatic and germ line variants by comparing these changes with those of normal samples [38]. In addition to the referred NGS technologies, the whole-transcriptome (RNA-Seq) and ChIP-Seq are utilized to detect the RNA editing, alternative splicing, fusion transcripts, and epigenetic alterations to gain an accurate and deep understanding of the cancer transcriptome and genome [39]. Many NGS-based researches are conducted to investigate the cancer progression, metastasis, tumor complexity, heterogeneity, fusion, and tumor evolution. Also, remarkable improvements are made for lung, breast, ovarian, liver, colorectal cancers, and leukemia [40-43]. For example, using the WGS in a patient with acute myeloid leukemia, an unfamiliar insertional fusion was detected that generated a classic bcr3 PML-RARA fusion gene and the findings changed the patient's treatment schedule [44]. Clinicians can design patient-specific probes that use DNA in the patient's blood serum to observe his/her improvement and check for any signs of relapse $[45,46]$. Although clinicians use the tumor biopsy as a gold standard for molecular diagnostic analysis, collection of fresh biopsies poses troubles for patients and researchers attempting to improve approaches to sequence other sources of tumor cells containing circulating tumor cells (CTCs) and circulating cell-free tumor DNA (ctDNA) detectable in plasma [47]. NGS analysis of cell-free tumor DNA suggests a strong procedure to identify the potential mutations in cancer and match patients with suitable targeted therapies. Furthermore, NGS analysis of this method allows visualization of the tumor evolution over time and treatment [47]. Therefore, NGS technologies are widely used in the clinics for cancer prognosis and diagnosis. The researchers hope to help the clinicians by discovering more biomarkers and developing targeted therapy to find the best personalized treatment [39]. It should be kept in mind that due to the variety in the cancer genomes and phenotypes, interpretation of the NGS data also require more analysis in combination with multi-omics data and clinicopathological data in a larger sample size to achieve comprehensive and efficient results [48].

\section{Breast Cancer}

Nowadays, the next generation sequencing is widely used in gene research and plays an important role in various cancers including breast, ovary, prostate, lung, pancreatic, liver, etc. Breast cancer is a disease of multifactorial inheritance, originating from the mutations of the normal cells. In recent years, researchers gained great improvements in breast cancer, especially using NGS. The NGS in breast cancer research is mostly used in three features: genome DNA sequence analysis (i.e. the WGS, exon sequencing, targeting gene sequencing), RNA transcription sequencing (i.e. the whole transcriptome analysis, small RNA sequencing, non-coding RNA analysis), and epigenetic sequencing [49]. Researchers reported several mutations or deletions of many genes related to breast cancer such as TP53, PTEN, RUNX1, CCND3, and PTPN22 [50].

D'Argenio et al., employed the NGS to detect BRCA1 and BRCA2 mutations and reported that this method was more sensitive than the traditional Sanger sequencing [51]. In another study by Ma et al., a novel mutation of BRCA2: c.8946_8947delAG (p.D2983FfsX34) was identified in a Chinese female by NGS [52]. Some studies revealed that specific miRNA abnormalities associated with specific types of breast cancer such as miR-10b, miR-9, miR-31, miR-126, and miR-335 are connected with breast cancer metastasis [53, 54].

Thompson et al., and Kiiski et al., demonstrated in two separate studies by whole-genome and exon sequencing that the rare mutations of FANCC, BLM, and FANCM genes were the potential susceptibility alleles of breast cancer [55, 56]. Pronina IV et al., using NGS, found a strong association between hypermethylation of MIR-127 and MIR-125b-1, and breast cancer progression [57].

About $5 \%-10 \%$ of breast cancers are hereditary. Genetic testing such as Sanger-based sequencing is used for hereditary cancers. But this traditional approach for genetic testing of hereditary cancers is time consuming and has low throughput and high cost [58]. Although BRCA1 and BRCA2 are the most identified hereditary cancer genes, only an estimated $5 \%-10 \%$ of breast cancers appear in 
individuals with inherited mutations in these genes in families [59, 60]. Currently, hereditary cancer testing is suggested by a variety of specialists both for affected and unaffected individuals [61, 62]. Multiple studies demonstrated that multi-gene testing identifies more individuals with hereditary breast cancer than testing for BRCA1/2 alone. The individuals with a suspected hereditary breast cancer, previously reported negative for BRCA1/2, were tested for additional genes and the results were positive in $2.9 \%-11.4 \%$ of the cases. In spite of the benefits of multi-gene testing, some argue that it is better to implement new DNA testing technology. Therefore, multi-gene testing allows for increased detection of hereditary cancer syndromes by utilizing the advantages of NGS technology [59]. Advances in NGS technology made it possible to test multiple genes simultaneously. Jalkh et al., studied 45 Lebanese patients with a family history of breast cancer using WES technique followed the Sanger sequencing validation. The results showed that 19 pathogenic mutations were found in 13 different genes such as ABCC12, APC, ATM, BRCA1, BRCA2, CDH1,ERCC6, MSH2, POLH, PRF1,SLX4, STK11, and TP53 [62]. Walsh et al., by the application of NGS technology, detected 21 genes associated with hereditary breast and ovarian cancers including BRCA1 and BRCA2, with inherited mutations [63]. Therefore, application of NGS in genetic testing for hereditary cancer syndromes is the first and closest step for its transition into clinical phase [64].

\section{Epigenetic}

Epigenetics is the science that studies the heritable modifications in gene expression that do not contain the DNA sequence [65]. There are two groups of epigenetic modifications: DNA methylation and post-translational modifications of histone. Recently, microRNA (miRNA) gene expression regulation was classified as epigenetic modifications [66]. Epigenomics implies the complete study of these alterations across the whole genome. Epigenetic mechanisms have major role in the growth of cells and normal development [67, 68]. Aberrant epigenetic changes can be contemplated as one of the causative factors in cancer [69]. Analysis of the epigenetic modifications is a key factor to understand the heterogeneity and complexity of human that despite possession of identical genome, various cell types express their genes in different ways (epigenome)
[70]. Therefore, it is highly important to investigate the profile of epigenome in a cell to be used as epigenetic biomarker for prognosis, diagnosis, and therapeutic applications [71, 72]. DNA methylation analysis is the most frequent application of NGS in the field of epigenetics. NGS technologies using methylated DNA immunoprecipitation (meDIP) and bisulphite methods can represent the properties of the methylated DNA to increase the understanding of specific cell-type expression patterns that cannot be explained at the genetic level [73]. Chromatin immunoprecipitation followed by NGS (ChIP-Seq) are applied to study the location of transcription factors, the transcription factor binding, and histone modifications, which comprises acetylation, methylation, phosphorylation, etc., at the wholegenome level [71].

Currently, by the combination of methylation array approach with massive DNA methylation analysis and RNA expression profiles, a large number of genes and miRNAs are identified under epigenetic regulation in many tumors such as colorectal, renal, prostate, and non-small cell lung cancer(NSCLC) [70, 74-76]. One of the earliest incentives to investigate the epigenetic modifications through NGS in clinical samples is achieving the extra information that can be gained from the pharmaco-epigenomics; it means that the presence of methylation at particular genes in certain cancers is associated with the clinical reaction to treatment that is extremely important to access the most effective treatment in the clinical epigenetics field [70].

\section{Prenatal Diagnosis}

Prenatal diagnosis contains features relating to the health of both the fetus and the parents [77]. Current methods including the combined test and invasive procedures (amniocentesis and chorionic villus sampling (CVS) used to screen the fetus for chromosomal abnormalities pose a risk to mother and fetus [78]. In addition to the risk, the rate of abortion related to CVS and amniocentesis is $1.0 \%$ to $2.0 \%$ [79] and the false positive rate of combined test is $5.0 \%-9.0 \%$ [80], and sometimes mothers with healthy fetuses may be selected for unnecessary invasive diagnostic tests that lead to spontaneous abortion [81]. Therefore, replacing the current invasive tests with Non Invasive Prenatal Diagnosis (NIPD) test reduces the risk and increases the detection rate for the three most prevalent aneuploidies; Down syndrome (trisomy 
21), Edward syndrome (trisomy 18), and Patau syndrome (trisomy 13) [78] . The NIPT is based on the finding of cell-free fetal DNA (cffDNA) in maternal plasma detectable as early as four weeks gestation [47, 82], making NIPT accessible earlier in pregnancy in comparison with invasive methods [83]. The cffDNA analysis with the NGS technology can be performed on a blood sample taken from the pregnant mother, that is cffDNA is sequenced and the reads are mapped to each chromosome and then counted, and it can be calculated whether a chromosome is over- or underrepresented [84, 85]. The main advantages of NGS for prenatal diagnosis are that NGS can be used to analyze non-invasive samples and has the capacity to recognize micro chromosomal abnormalities [86].

\section{Personalized Medicine}

Traditional medical model to detect and treat disorders is highly expensive for patients and healthcare system. Therefore, it is necessary to apply an innovative approach such as NGS technology to accelerate the early detection of disorders [87]. Personalized medicine (PM) is an approach to medical diagnosis, treatment, and risk assessment based on an individual's genetic in order to improve health care for the individual and predict which medical treatments are proper for the patient $[88,89]$. Application of the PM can decline financial and time expenditures, and increase the quality of life in patients [90]. PM separates individuals into subpopulations that show different responses to a therapeutic agent for their specific disease. For example, Herceptin is a useful drug for patients with breast cancer and elevated expression of HER2. However, some patients with increased HER2 are resistant to Herceptin due to mutations to the HER2 gene. Therefore, molecular identification of patients with breast cancer allows for the optimal application of Herceptin through stratification of the patients [91].

To date, many studies applied NGS methods for personalized treatment of cancer. For example, NGS is used to treat pancreatic cancer [64]. It is also used to detect epidermal growth factor receptor (EGFR) deletions in NSCLC [92]. There is general agreement that NGS should be the standard method when several genes should be tested in the same patient. For instance, patients with estrogen receptorpositive breast cancer should be tested for mutations in PIK3CA, ESR1, AKT1, and ERBB2. It seems that NGS possibly becomes the standard method to diagnose genomic alterations in breast cancer [47].

\section{Clinical Microbiology}

NGS is applied in medical microbiology as a powerful tool for molecular case finding, outbreak management, bacterial typing, determination of biological properties such as the presence of virulence factors, fast recognition of bacteria through the 16S rRNA region that requires bacterial isolates, antimicrobial agent resistance and metagenomics approaches that may be applied directly on the sample [93, 94]. NGS technology, using the WGS approach, is performed to detect highly-virulent bacteria; for example, Shiga toxin-producing Escherichia coli that is liable for great outbreaks [95]. Another application of NGS technology in medical microbiology is molecular case finding performed within a few hours. Some cases are reported in Denmark, Germany, and the Netherlands in hospitalized patients to screen the mcr-1 gene in Enterobacteriaceae isolates, which is in charge of colistin resistance [96-98].

NGS is also helpful to identify novel resistance genes such as antibiotic resistance genes in bacteria [99]. NGS, using the culture-independent methods, allows researchers to sequence a number of pathogens directly from biological samples [100]. This approach is referred to as metagenomics and can detect all micro-organisms in a clinical sample without the prior need for culturing [101]. There are some reports about the metagenomics strategy that was favorably performed to sequence the eukaryote Plasmodium falciparum from a blood cell-depleted sample and the bioterrorism agent Francisella tularensis from abscess pus $[102,103]$.

NGS is an ideal tool in epidemiological typing since the typing of bacterial strains is crucial to study the transmission pathways and identify the single genomic alterations between two isolates [104]. Identification of the toxins known to cause severe diseases such as toxic shock syndrome caused by Streptococcus spp. is an important field in clinical microbiology performed by WGS [105]. Therefore, NGS technologies are helpful in various fields in the clinical microbiology.

\section{Future Directions}

In the near future, NGS technologies are very helpful for clinical purposes. The fast and high throughput sequencing method is considered as a good diagnostic and prognostic tool, which helps 
clinicians determine specific features in each patient, and opens the road towards personalized medicine. But similar to other new technologies, there are still many technical, analytical, and ethical issues that need further processing.

\section{CONCLUSIONS}

NGS technologies represent a revolutionary tool for numerous applications and can produce multiple repeats in a single run. These technologies are increasingly used in various fields such as genome and transcriptome sequencing, polymorphism detection, mutation mapping, DNA methylation, histone modifications, alternative splicing identification, small RNA profiling, DNA-protein interactions, protein-protein interactions, sequencing of the mitochondrial genome, personal genomics, and diagnosis and treatment of common diseases due to their speed, cost-effectiveness, and high-throughput nature. DNA sequencing technologies are used as a clinical diagnostic tool and it takes the support systems at least a decade to develop and validate data analysis and interpretation for clinical diagnostic use.

\section{ACKNOWLEDGMENTS}

The current review was supported by Saman Tajhiz Noor Laboratory Diagnostic Network Company, Tehran, Iran.

\section{CONFLICT OF INTEREST}

The authors declared no conflict of interest.

\section{ETHICS APPROVAL}

The current study was approved by the Ethics Committee of Saman Tajhiz Noor Laboratory Diagnostic Network Company.

\section{REFERENCES}

1. Dovichi NJ. DNA sequencing by capillary electrophoresis. Electrophoresis. 1997;18(12-13):2393-9. DOI: 10.1002/ elps.1150181229 PMID: 9456053

2. Maxam AM, Gilbert W. A new method for sequencing DNA. Proceedings of the National Academy of Sciences of the United States of America. 1977;74(2):560-4. PMID: 265521

3. Sanger F, Nicklen S, Coulson AR. DNA sequencing with chain-terminating inhibitors. Proceedings of the National Academy of Sciences of the United States of America. 1977;74(12):5463-7. PMID: 271968

4. Kim KM, Park JH, Bhattacharya D, Yoon HS. Applications of next-generation sequencing to unravelling the evolutionary history of algae. Int J Syst Evol Microbiol. 2014;64(Pt 2):333-45. DOI: 10.1099/ijs.0.054221-0 PMID: 24505071
5. Biesecker LG, Burke W, Kohane I, Plon SE, Zimmern R. Next-generation sequencing in the clinic: are we ready? Nat Rev Genet. 2012;13(11):818-24. DOI: 10.1038/nrg3357 PMID: 23076269

6. Chan EY. Advances in sequencing technology. Mutat Res. 2005;573(1-2):13-40. DOI: 10.1016/j.mrfmmm.2005.01.004 PMID: 15829235

7. Shendure J, Ji H. Next-generation DNA sequencing. Nat Biotechnol. 2008;26(10):1135-45. DOI: 10.1038/nbt1486 PMID: 18846087

8. Kamps R, Brandao RD, Bosch BJ, Paulussen AD, Xanthoulea S, Blok MJ, et al. Next-Generation Sequencing in Oncology: Genetic Diagnosis, Risk Prediction and Cancer Classification. Int J Mol Sci. 2017;18(2):308. DOI: 10.3390/ijms18020308 PMID: 28146134

9. Morozova O, Marra MA. Applications of next-generation sequencing technologies in functional genomics. Genomics. 2008;92(5):255-64. DOI: 10.1016/j.ygeno.2008.07.001 PMID: 18703132

10. Cottrell CE, Al-Kateb H, Bredemeyer AJ, Duncavage EJ, Spencer DH, Abel HJ, et al. Validation of a next-generation sequencing assay for clinical molecular oncology. J Mol Diagn. 2014;16(1):89-105. DOI: 10.1016/j. jmoldx.2013.10.002 PMID: 24211365

11. Matthijs G, Souche E, Alders M, Corveleyn A, Eck S, Feenstra I, et al. Guidelines for diagnostic next-generation sequencing. Eur J Hum Genet. 2016;24(1):2-5. PMID: $\underline{26508566}$

12. Rehm HL, Bale SJ, Bayrak-Toydemir P, Berg JS, Brown KK, Deignan JL, et al. ACMG clinical laboratory standards for next-generation sequencing. Genet Med. 2013;15(9):733-47. DOI: 10.1038/gim.2013.92 PMID: 23887774

13. Mardis ER. The impact of next-generation sequencing technology on genetics. Trends Genet. 2008;24(3):133-41. DOI: 10.1016/j.tig.2007.12.007 PMID: 18262675

14. Mardis ER. Next-generation DNA sequencing methods. Annu Rev Genomics Hum Genet. 2008;9:387-402. DOI: 10.1146/annurev.genom.9.081307.164359 PMID: $\underline{18576944}$

15. Head SR, Komori HK, LaMere SA, Whisenant T, Van Nieuwerburgh F, Salomon DR, et al. Library construction for next-generation sequencing: overviews and challenges. Biotechniques. 2014;56(2):61-4, 6, 8, passim. DOI: 10.2144/000114133 PMID: 24502796

16. Dabney J, Meyer M. Length and GC-biases during sequencing library amplification: a comparison of various polymerase-buffer systems with ancient and modern DNA sequencing libraries. Biotechniques. 2012;52(2):87. DOI: 10.2144/000113809 PMID: 22313406

17. Gilissen C, Hoischen A, Brunner HG, Veltman JA. Disease gene identification strategies for exome sequencing. Eur J Hum Genet. 2012;20(5):490-7. DOI: 10.1038/ ejhg.2011.258 PMID: 22258526

18. Buermans HP, den Dunnen JT. Next generation sequencing technology: Advances and applications. Biochimica et biophysica acta. 2014;1842(10):1932-41. DOI: 10.1016/j. bbadis.2014.06.015 PMID: 24995601 
19. Patel RK, Jain M. NGS QC Toolkit: a toolkit for quality control of next generation sequencing data. PLoS One. 2012;7(2):e30619. DOI: 10.1371/journal.pone.0030619 PMID: 22312429

20. Pandey RV, Pabinger S, Kriegner A, Weinhausel A. ClinQC: a tool for quality control and cleaning of Sanger and NGS data in clinical research. BMC bioinformatics. 2016;17:56. DOI: 10.1186/s12859-016-0915-y PMID: $\underline{26830926}$

21. Rehm HL, Bale SJ, Bayrak-Toydemir P, Berg JS, Brown KK, Deignan JL, et al. Working Group of the American College of Medical G and Genomics Laboratory Quality Assurance C. ACMG clinical laboratory standards for next-generation sequencing. Genet Med. 2013;15:733-47. DOI: $10.1038 /$ gim.2013.92

22. Ellard S, Charlton R, Lindsay H, Camm N, Watson C, Abbs $\mathrm{S}$, et al. Practice guidelines for targeted Next Generation Sequencing analysis and interpretation. Assoc Clin Genet Sci. 2012.

23. Trivedi UH, Cezard T, Bridgett S, Montazam A, Nichols J, Blaxter M, et al. Quality control of next-generation sequencing data without a reference. Front Genet. 2014;5(111):111. DOI: 10.3389/fgene.2014.00111 PMID: $\underline{24834071}$

24. Keegan KP, Trimble WL, Wilkening J, Wilke A, Harrison T, D'Souza M, et al. A platform-independent method for detecting errors in metagenomic sequencing data: DRISEE. PLoS Comput Biol. 2012;8(6):e1002541. DOI: 10.1371/journal.pcbi.1002541 PMID: 22685393

25. Schroder J, Bailey J, Conway T, Zobel J. Reference-free validation of short read data. PLoS One. 2010;5(9):e12681. DOI: 10.1371/journal.pone.0012681 PMID: 20877643

26. Hert DG, Fredlake CP, Barron AE. Advantages and limitations of next-generation sequencing technologies: a comparison of electrophoresis and non-electrophoresis methods. Electrophoresis. 2008;29(23):4618-26. DOI: 10.1002/ elps.200800456 PMID: 19053153

27. Green RE, Krause J, Ptak SE, Briggs AW, Ronan MT, Simons JF, et al. Analysis of one million base pairs of Neanderthal DNA. Nature. 2006;444(7117):330-6. DOI: 10.1038/nature05336 PMID: 17108958

28. Hall N. Advanced sequencing technologies and their wider impact in microbiology. J Exp Biol. 2007;210(Pt 9):151825. DOI: $10.1242 /$ jeb.001370 PMID: 17449817

29. Simon R, Roychowdhury S. Implementing personalized cancer genomics in clinical trials. Nat Rev Drug Discov. 2013;12(5):358-69. DOI: 10.1038/nrd3979 PMID: $\underline{23629504}$

30. Jamuar SS, Tan EC. Clinical application of next-generation sequencing for Mendelian diseases. Hum Genomics. 2015;9(1):10. DOI: 10.1186/s40246-015-0031-5 PMID: $\underline{26076878}$

31. Rehm HL. Disease-targeted sequencing: a cornerstone in the clinic. Nat Rev Genet. 2013;14(4):295-300. DOI: 10.1038/nrg3463 PMID: 23478348

32. Mardis ER. A decade's perspective on DNA sequencing technology. Nature. 2011;470(7333):198-203. DOI: 10.1038/nature09796 PMID: 21307932
33. Wang Z, Gerstein M, Snyder M. RNA-Seq: a revolutionary tool for transcriptomics. Nat Rev Genet. 2009;10(1):57-63. DOI: $10.1038 / n r g 2484$ PMID: 19015660

34. Xuan J, Yu Y, Qing T, Guo L, Shi L. Next-generation sequencing in the clinic: promises and challenges. Cancer letters. 2013;340(2):284-95. DOI: 10.1016/j.canlet.2012.11.025 PMID: 23174106

35. Behjati S, Tarpey PS. What is next generation sequencing? Arch Dis Child Educ Pract Ed. 2013;98(6):236-8. DOI: 10.1136/archdischild-2013-304340 PMID: 23986538

36. Seifi M, Ghasemi A, Raeisi S, Heidarzadeh S. Application of Next-generation Sequencing in Clinical Molecular Diagnostics. Brazilian Archives of Biology and Technology. 2017;60(0):e17160414. DOI: 10.1590/1678-4324$\underline{2017160414}$

37. Meyerson M, Gabriel S, Getz G. Advances in understanding cancer genomes through second-generation sequencing. Nat Rev Genet. 2010;11(10):685-96. DOI: 10.1038/ nrg2841 PMID: 20847746

38. Meldrum C, Doyle MA, Tothill RW. Next-generation sequencing for cancer diagnostics: a practical perspective. Clin Biochem Rev. 2011;32(4):177-95. PMID: 22147957

39. Shyr D, Liu Q. Next generation sequencing in cancer research and clinical application. Biol Proced Online. 2013;15(1):4. DOI: 10.1186/1480-9222-15-4 PMID: 23406336

40. Cancer Genome Atlas Network. Comprehensive molecular portraits of human breast tumours. Nature. 2012;490(7418):61-70. DOI: 10.1038/nature11412 PMID: 23000897

41. Cancer Genome Atlas Network. Comprehensive molecular characterization of human colon and rectal cancer. Nature. 2012;487(7407):330-7. DOI: 10.1038/nature11252 PMID: $\underline{22810696}$

42. Cancer Genome Atlas Research Network. Integrated genomic analyses of ovarian carcinoma. Nature. 2011;474(7353):609-15. DOI: 10.1038/nature10166 PMID: 21720365

43. Cancer Genome Atlas Research N. Comprehensive genomic characterization of squamous cell lung cancers. Nature. 2012;489(7417):519-25. DOI: 10.1038/nature11404 PMID: 22960745

44. Welch JS, Westervelt P, Ding L, Larson DE, Klco JM, Kulkarni S, et al. Use of whole-genome sequencing to diagnose a cryptic fusion oncogene. JAMA. 2011;305(15):1577-84.

45. Russnes HG, Navin N, Hicks J, Borresen-Dale A-L. Insight into the heterogeneity of breast cancer through next-generation sequencing. J Clin Invest. 2011;121(10):3810. DOI: 10.1172/JCI57088 PMID: 21965338

46. Samuel N, Hudson TJ. Translating genomics to the clinic: implications of cancer heterogeneity. Clin Chem. 2013;59(1):127-37. DOI: $10.1373 /$ clinchem.2012.184580 PMID: 23151419

47. Cummings CA, Peters E, Lacroix L, Andre F, Lackner MR. The Role of Next-Generation Sequencing in Enabling Personalized Oncology Therapy. Clin Transl Sci. 2016;9(6):283-92. DOI: 10.1111/cts.12429 PMID: 


\section{9}

48. Nakagawa H, Wardell CP, Furuta M, Taniguchi H, Fujimoto A. Cancer whole-genome sequencing: present and future. Oncogene. 2015;34(49):5943-50. DOI: 10.1038/ onc. 2015.90 PMID: 25823020

49. Ma R, Gong J, Jiang X. Novel applications of next-generation sequencing in breast cancer research. Genes Dis. 2017;4(3):149-53. DOI: 10.1016/j.gendis.2017.07.003 PMID: 30258916

50. Banerji S, Cibulskis K, Rangel-Escareno C, Brown KK, Carter SL, Frederick AM, et al. Sequence analysis of mutations and translocations across breast cancer subtypes. Nature. 2012;486(7403):405-9. DOI: 10.1038/nature11154 PMID: 22722202

51. D’Argenio V, Frisso G, Precone V, Boccia A, Fienga A, Pacileo G, et al. DNA sequence capture and next-generation sequencing for the molecular diagnosis of genetic cardiomyopathies. J Mol Diagn. 2014;16(1):32-44. DOI: 10.1016/j.jmoldx.2013.07.008 PMID: 24183960

52. Ma J, Yang J, Jian W, Wang X, Xiao D, Xia W, et al. A novel loss-of-function heterozygous BRCA2 c. 8946_8947delAG mutation found in a Chinese woman with family history of breast cancer. J Cancer Res Clin Oncol. 2017;143(4):6317. DOI: 10.1007/s00432-016-2327-9 PMID: 28058502

53. Farazi TA, Horlings HM, Ten Hoeve JJ, Mihailovic A, Halfwerk H, Morozov P, et al. MicroRNA sequence and expression analysis in breast tumors by deep sequencing. Cancer Res. 2011;71(13):4443-53. DOI: 10.1158/00085472.CAN-11-0608 PMID: 21586611

54. Li S, Yang C, Zhai L, Zhang W, Yu J, Gu F, et al. Deep sequencing reveals small RNA characterization of invasive micropapillary carcinomas of the breast. Breast Cancer Res Treat. 2012;136(1):77-87. DOI: 10.1007/s10549-0122166-6 PMID: 22976804

55. Kiiski JI, Pelttari LM, Khan S, Freysteinsdottir ES, Reynisdottir I, Hart SN, et al. Exome sequencing identifies FANCM as a susceptibility gene for triple-negative breast cancer. Proc Natl Acad Sci. 2014;111(42):15172-7. DOI: 10.1073/pnas.1407909111 PMID: 25288723

56. Thompson ER, Doyle MA, Ryland GL, Rowley SM, Choong DYH, Tothill RW, et al. Exome sequencing identifies rare deleterious mutations in DNA repair genes FANCC and BLM as potential breast cancer susceptibility alleles. PLoS Genetics. 2012;8(9):e1002894. DOI: 10.1371/journal.pgen.1002894 PMID: 23028338

57. Pronina IV, Loginov VI, Burdennyy AM, Fridman MV, Senchenko VN, Kazubskaya TP, et al. DNA methylation contributes to deregulation of 12 cancer-associated microRNAs and breast cancer progression. Gene. 2017;604:1-8. DOI: 10.1016/j.gene.2016.12.018 PMID: 27998789

58. Price KS, Svenson A, King E, Ready K, Lazarin GA. Inherited Cancer in the Age of Next-Generation Sequencing. Biol Res Nurs. 2018;20(2):192-204. DOI: $\underline{10.1177 / 1099800417750746}$ PMID: 29325452

59. Kapoor NS, Curcio LD, Blakemore CA, Bremner AK, McFarland RE, West JG, et al. Multigene panel testing detects equal rates of pathogenic BRCA1/2 mutations and has a higher diagnostic yield compared to limited BRCA1/2 analysis alone in patients at risk for hereditary breast cancer. Ann Surg Oncol. 2015;22(10):3282-8. DOI: 10.1245/ s10434-015-4754-2 PMID: 26219241

60. Melchor L, Benitez J. The complex genetic landscape of familial breast cancer. Hum Genet. 2013;132(8):845-63. DOI: 10.1007/s00439-013-1299-y PMID: 23552954

61. Bellcross CA, Kolor K, Goddard KAB, Coates RJ, Reyes M, Khoury MJ. Awareness and utilization of BRCA1/2 testing among US primary care physicians. Am J Prev Med. 2011;40(1):61-6. DOI: 10.1016/j.amepre.2010.09.027 PMID: 21146769

62. Jalkh N, Chouery E, Haidar Z, Khater C, Atallah D, Ali $\mathrm{H}$, et al. Next-generation sequencing in familial breast cancer patients from Lebanon. BMC Med Genomics. 2017;10(1):8. DOI: 10.1186/s12920-017-0244-7 PMID: 28202063

63. Walsh T, Lee MK, Casadei S, Thornton AM, Stray SM, Pennil C, et al. Detection of inherited mutations for breast and ovarian cancer using genomic capture and massively parallel sequencing. Proc Natl Acad Sci. 2010;107(28):1262933. DOI: 10.1073/pnas.1007983107 PMID: 20616022

64. Guan YF, Li GR, Wang RJ, Yi YT, Yang L, Jiang D, et al. Application of next-generation sequencing in clinical oncology to advance personalized treatment of cancer. Chinese journal of cancer. 2012;31(10):463-70. DOI: 10.5732/ cjc.012.10216 PMID: 22980418

65. Goldberg AD, Allis CD, Bernstein E. Epigenetics: a landscape takes shape. Cell. 2007;128(4):635-8. DOI: 10.1016/j.cell.2007.02.006 PMID: 17320500

66. Callinan PA, Feinberg AP. The emerging science of epigenomics. Hum Mol Genet. 2006;15 Spec No 1(suppl_1):R95-101. DOI: 10.1093/hmg/ddl095 PMID: $\underline{16651376}$

67. Esteller M. The necessity of a human epigenome project. Carcinogenesis. 2006;27(6):1121-5. DOI: 10.1093/carcin/ bg1033 PMID: 16699174

68. Jones PA, Baylin SB. The epigenomics of cancer. Cell. 2007;128(4):683-92. DOI: 10.1016/j.cell.2007.01.029 PMID: 17320506

69. Feinberg AP, Tycko B. The history of cancer epigenetics. Nature reviews Cancer. 2004;4(2):143-53. DOI: 10.1038/ $\underline{\text { nrc1279 PMID: } 14732866}$

70. Soto J, Rodriguez-Antolin C, Vallespín E, de Castro Carpeno J, de Caceres II. The impact of next-generation sequencing on the DNA methylation-based translational cancer research. Transl Res. 2016;169:1-18. e1. DOI: 10.1016/j.trsl.2015.11.003 PMID: 26687736

71. Laird PW. The power and the promise of DNA methylation markers. Nature reviews Cancer. 2003;3(4):253-66. DOI: 10.1038/nrc1045 PMID: 12671664

72. Mulero-Navarro S, Esteller M. Epigenetic biomarkers for human cancer: the time is now. Crit Rev Oncol Hematol. 2008;68(1):1-11. DOI: 10.1016/j.critrevonc.2008.03.001 PMID: 18430583

73. Neff T, Armstrong SA. Chromatin maps, histone modifications and leukemia. Leukemia. 2009;23(7):1243-51. DOI: 10.1038/leu.2009.40 PMID: 19322211

74. De Caceres II, Cortes-Sempere M, Moratilla C, Macha- 
do-Pinilla R, Rodriguez-Fanjul V, Manguan-Garcia C, et al. IGFBP-3 hypermethylation-derived deficiency mediates cisplatin resistance in non-small-cell lung cancer. Oncogene. 2010;29(11):1681-90. DOI: 10.1038/onc.2009.454 PMID: 20023704

75. De Caceres II, Dulaimi E, Hoffman AM, Al-Saleem T, Uzzo RG, Cairns P. Identification of novel target genes by an epigenetic reactivation screen of renal cancer. Cancer Res. 2006;66(10):5021-8. DOI: 10.1158/0008-5472.CAN05-3365 PMID: 16707423

76. Ibragimova I, Ibanez de Caceres I, Hoffman AM, Potapova A, Dulaimi E, Al-Saleem T, et al. Global reactivation of epigenetically silenced genes in prostate cancer. Cancer Prev Res (Phila). 2010;3(9):1084-92. DOI: 10.1158/19406207.CAPR-10-0039 PMID: 20699414

77. Reinstein E. Challenges of using next generation sequencing in newborn screening. Genet Res (Camb). 2015;97:e21. DOI: $10.1017 /$ S0016672315000178 PMID: 26521961

78. Avent ND, Webb A, Madgett TE, Miran T, Sillence K, Kaushik N, et al. Non invasive prenatal diagnosis of aneuploidy: next generation sequencing or fetal DNA enrichment? Balkan J Med Genet. 2012;15(Supplement):17-26. DOI: $10.2478 / \mathrm{v} 10034-012-0013-\mathrm{Z}$ PMID: 24052738

79. Mujezinovic F,Alfirevic Z. Procedure-related complications of amniocentesis and chorionic villous sampling: a systematic review. Obstetrics and gynecology. 2007;110(3):68794. DOI: 10.1097/01.AOG.0000278820.54029.e3 PMID: $\underline{17766619}$

80. Go ATJI, van Vugt JMG, Oudejans CBM. Non-invasive aneuploidy detection using free fetal DNA and RNA in maternal plasma: recent progress and future possibilities. Hum Reprod Update. 2010;17(3):372-82. DOI: 10.1093/ humupd/dmq054 PMID: 21076134

81. Hahn S, Lapaire O, Tercanli S, Kolla V, Hosli I. Determination of fetal chromosome aberrations from fetal DNA in maternal blood: has the challenge finally been met? Expert Rev Mol Med. 2011;13:e16. DOI: 10.1017/ S1462399411001852 PMID: 21542948

82. Illanes S, Denbow M, Kailasam C, Finning K, Soothill PW. Early detection of cell-free fetal DNA in maternal plasma. Early Hum Dev. 2007;83(9):563-6. DOI: 10.1016/j.earlhumdev.2006.11.001 PMID: 17234369

83. Lo YM, Corbetta N, Chamberlain PF, Rai V, Sargent IL, Redman CW, et al. Presence of fetal DNA in maternal plasma and serum. Lancet. 1997;350(9076):485-7. DOI: 10.1016/S0140-6736(97)02174-0 PMID: 9274585

84. Chen EZ, Chiu RW, Sun H, Akolekar R, Chan KC, Leung TY, et al. Noninvasive prenatal diagnosis of fetal trisomy 18 and trisomy 13 by maternal plasma DNA sequencing. PLoS One. 2011;6(7):e21791. DOI: 10.1371/journal. pone.0021791 PMID: 21755002

85. Fan HC, Blumenfeld YJ, Chitkara U, Hudgins L, Quake SR. Noninvasive diagnosis of fetal aneuploidy by shotgun sequencing DNA from maternal blood. Proceedings of the National Academy of Sciences of the United States of America. 2008;105(42):16266-71. DOI: 10.1073/ pnas.0808319105 PMID: 18838674

86. Kotsopoulou I, Tsoplou P, Mavrommatis K, Kroupis C.
Non-invasive prenatal testing (NIPT): limitations on the way to become diagnosis. Diagnosis (Berl). 2015;2(3):14158. DOI: 10.1515/dx-2015-0002 PMID: 29540035

87. Gonzalez-Garay ML. The road from next-generation sequencing to personalized medicine. Per Med. 2014;11(5):523-44. DOI: 10.2217/pme.14.34 PMID: $\underline{26000024}$

88. Beigh MM. Next-Generation Sequencing: The Translational Medicine Approach from "Bench to Bedside to Population”. Medicines (Basel). 2016;3(2):14. DOI: 10.3390/ medicines3020014 PMID: 28930123

89. Chan IS, Ginsburg GS. Personalized medicine: progress and promise. Annu Rev Genomics Hum Genet. 2011;12:21744. DOI: 10.1146/annurev-genom-082410-101446 PMID: 21721939

90. Mathur S, Sutton J. Personalized medicine could transform healthcare. Biomed Rep. 2017;7(1):3-5. DOI: 10.3892/ br.2017.922 PMID: 28685051

91. Claret FX, Vu TT. Trastuzumab: updated mechanisms of action and resistance in breast cancer. Front Oncol. 2012;2:62. DOI: 10.3389/fonc.2012.00062 PMID: 22720269

92. Marchetti A, Del Grammastro M, Filice G, Felicioni L, Rossi G, Graziano P, et al. Complex mutations \& subpopulations of deletions at exon 19 of EGFR in NSCLC revealed by next generation sequencing: potential clinical implications. PLoS One. 2012;7(7):e42164. DOI: 10.1371/ journal.pone.0042164 PMID: 22848739

93. Bertelli C, Greub G. d. Clin Microbiol Infect. 2013;19(9):803-13. DOI: 10.1111/1469-0691.12217 PMID: 23601179

94. Deurenberg RH, Bathoorn E, Chlebowicz MA, Couto N, Ferdous M, García-Cobos S, et al. Application of next generation sequencing in clinical microbiology and infection prevention. J Biotechnol. 2017;243:16-24. DOI: 10.1016/j. jbiotec.2016.12.022 PMID: 28042011

95. Zhou K, Ferdous M, de Boer RF, Kooistra-Smid AM, Grundmann H, Friedrich AW, et al. The mosaic genome structure and phylogeny of Shiga toxin-producing Escherichia coli O104: $\mathrm{H} 4$ is driven by short-term adaptation. Clin Microbiol Infect. 2015;21(5):468. e7-. e18. DOI: 10.1016/j.cmi.2014.12.009 PMID: 25656624

96. Falgenhauer L, Waezsada SE, Yao Y, Imirzalioglu C, Kasbohrer A, Roesler U, et al. Colistin resistance gene mcr-1 in extended-spectrum beta-lactamase-producing and carbapenemase-producing Gram-negative bacteria in Germany. Lancet Infect Dis. 2016;16(3):282-3. DOI: 10.1016/ S1473-3099(16)00009-8 PMID: 26774242

97. Hasman H, Hammerum AM, Hansen F, Hendriksen RS, Olesen B, Agerso Y, et al. Detection of mcr-1 encoding plasmid-mediated colistin-resistant Escherichia coli isolates from human bloodstream infection and imported chicken meat, Denmark 2015. Euro Surveill. 2015;20(49). DOI: 10.2807/1560-7917.ES.2015.20.49.30085 PMID: 26676364

98. Kluytmans-van den Bergh MF, Huizinga P, Bonten MJ, Bos M, De Bruyne K, Friedrich AW, et al. Presence of mcr-1-positive Enterobacteriaceae in retail chicken meat but not in humans in the Netherlands since 2009. Euro Surveill. 2016;21(9). DOI: 10.2807/1560-7917. 
ES.2016.21.9.30149 PMID: 26967540

99. Nijhuis RH, Oueslati S, Zhou K, Bosboom RW, Rossen JW, Naas T. OXY-2-15, a novel variant showing increased ceftazidime hydrolytic activity. J Antimicrob Chemother. 2015;70(5):1429-33. DOI: 10.1093/jac/dkv002 PMID: $\underline{25630648}$

100. Hasman H, Saputra D, Sicheritz-Ponten T, Lund O, Svendsen CA, Frimodt-Moller N, et al. Rapid whole-genome sequencing for detection and characterization of microorganisms directly from clinical samples. J Clin Microbiol. 2014;52(1):139-46. DOI: 10.1128/JCM.02452-13 PMID: $\underline{24172157}$

101. Bragg L, Tyson GW. Metagenomics using next-generation sequencing. Methods in molecular biology (Clifton, NJ). 2014;1096:183-201. DOI: 10.1007/978-1-62703-712-9 15 PMID: 24515370

102. Auburn S, Campino S, Clark TG, Djimde AA, Zongo I, Pinches R, et al. An effective method to purify Plasmodi- um falciparum DNA directly from clinical blood samples for whole genome high-throughput sequencing. PloS one. 2011;6(7):e22213. DOI: 10.1371/journal.pone.0022213 PMID: 21789235

103. Kuroda M, Sekizuka T, Shinya F, Takeuchi F, Kanno T, Sata $\mathrm{T}$, et al. Detection of a possible bioterrorism agent, Francisella sp., in a clinical specimen by use of next-generation direct DNA sequencing. J Clin Microbiol. 2012;50(5):1810-2. DOI: 10.1128/JCM.06715-11 PMID: 22337979

104. Rasko DA, Worsham PL, Abshire TG, Stanley ST, Bannan JD, Wilson MR, et al. Bacillus anthracis comparative genome analysis in support of the Amerithrax investigation. Proceedings of the National Academy of Sciences of the United States of America. 2011;108(12):5027-32. DOI: 10.1073/pnas.1016657108 PMID: 21383169

105. Lappin E, Ferguson AJ. Gram-positive toxic shock syndromes. Lancet Infect Dis. 2009;9(5):281-90. DOI: 10.1016/S1473-3099(09)70066-0 PMID: 19393958 